\title{
Role of the anterior cingulate cortex in the retrieval of novel object recognition memory after a long delay
}

\author{
Marie A. Pezze, ${ }^{1}$ Hayley J. Marshall, ${ }^{2}$ Kevin CF. Fone, ${ }^{2}$ and Helen J. Cassaday ${ }^{1}$ \\ ${ }^{1}$ School of Psychology; ${ }^{2}$ School of Life Sciences, The University of Nottingham, University Park, Nottingham, NG7 2RD, \\ United Kingdom
}

\begin{abstract}
Previous in vivo electrophysiological studies suggest that the anterior cingulate cortex (ACgx) is an important substrate of novel object recognition (NOR) memory. However, intervention studies are needed to confirm this conclusion and permanent lesion studies cannot distinguish effects on encoding and retrieval. The interval between encoding and retrieval tests may also be a critical determinant of the role of the ACgx. The current series of experiments used micro-infusion of the $\mathrm{GABA}_{\mathrm{A}}$ receptor agonist, muscimol, into $\mathrm{ACgx}$ to reversibly inactivate the area and distinguish its role in encoding and retrieval. ACgx infusions of muscimol, before encoding did not alter NOR assessed after a delay of 20 min or $24 \mathrm{~h}$. However, when infused into the ACgx before retrieval muscimol impaired NOR assessed after a delay of $24 \mathrm{~h}$, but not after a 20-min retention test. Together these findings suggest that the ACgx plays a time-dependent role in the retrieval, but not the encoding, of NOR memory, neuronal activation being required for the retrieval of remote $24 \mathrm{~h}$ old), but not recent (20 min old) visual memory.
\end{abstract}

Humans and other mammals have a natural tendency to explore novel stimuli such as those provided by new environments or objects. For example, rats given the choice between a novel and familiar object spontaneously spend more time exploring the novel object. To discriminate between novel and familiar stimuli requires the ability to remember previously encountered stimuli (Ennaceur and Delacour 1988). As this is an innate tendency, novel object recognition (NOR) procedures offer advantages over many learning and memory tasks in that NOR can be studied without training or the use of positive (e.g., food) or negative (e.g., footshock) reinforcers (Lyon et al. 2012). Furthermore, by selecting an appropriate phase for drug administration, the task can be utilized to distinguish the effects of neuropharmacological manipulations on acquisition, consolidation, and/or retrieval of visual learning and memory (King et al. 2004; Pezze et al. 2015).

The neurobiological substrates of recognition memory have been extensively studied (Winters et al. 2008; Brown et al. 2010; Warburton and Brown 2010) and a key role has been identified for plasticity within the perirhinal cortex (Bussey et al. 1999; Brown and Aggleton 2001; Banks et al. 2012). The prefrontal cortex (PFC) is also critically involved in object discrimination. For example, expression of c-Fos protein in the PFC was elevated when rats were shown novel objects as compared with familiar objects (Zhu et al. 1995b). Also, while lesions and inactivation of the medial prefrontal cortex (mPFC) particularly impair recognition memory requiring judgement about recency and object location (Hannesson et al. 2004a,b; Barker et al. 2007; Nelson et al. 2011), there is also electrophysiological evidence that mechanisms within the anterior cingulate cortex (ACgx) region of the mPFC contribute to NOR based simply on object identity. Both in rats and monkeys, it has been shown that the responses of many neurons in the ACgx signal object familiarity (Zhu et al. 1995a; Rainer and Miller 2000; Xiang and Brown 2004). Single neuron firing recorded from the ACgx of mice has also been

\section{Corresponding author: m.pezze@nottingham.ac.uk}

Article is online at http://www.learnmem.org/cgi/doi/10.1101//m.044784. 116. Freely available online through the Learning \& Memory Open Access option. shown to correlate with the expression/retrieval of aspects of object recognition (Weible et al. 2009) and has been suggested to reflect consolidated object memory (Weible et al. 2012).

These electrophysiological recording studies contrast with previous lesion studies that failed to support the hypothesis that ACgx is involved in object memory. In monkeys, for example, object memory processes evaluated by delayed nonmatching-tosample were left unaffected by lesion of the ACgx (Meunier et al. 1997). Moreover, in rats, previous work demonstrated that performance of spontaneous NOR was unaltered by ACgx lesions (Ennaceur et al. 1997). The use of permanent lesions of the ACgx, as opposed to temporary pharmacological inactivation, may explain why these experiments failed to reveal a contribution of the ACgx to NOR. As lesion effects are usually tested after a period of recovery from surgery, adaptive process could occur that obscure the primary effect of the lesion (cf. Wang et al. 2015 and Bast and Feldon 2003). Another factor that may have contributed to this discrepancy between electrophysiological and lesion studies is the different retention delay times used in these studies. In the Weible et al. (2012) study, for example, the electrophysiological recording correlated with expression/retrieval of recognition memory after delays between $6 \mathrm{~h}$ and $1 \mathrm{mo}$, while in other previous lesion studies the delay between encoding and retrieval was shorter than 15 min (Ennaceur et al. 1997; Meunier et al. 1997).

Therefore, the present study was undertaken to further examine the role of the ACgx in the rat in NOR. We used microinfusion of the $\mathrm{GABA}_{\mathrm{A}}$ receptor agonist, muscimol (Majchrzak and Di Scala, 2000), to explore the effect of reversible neuronal inactivation of the ACgx on the encoding and retrieval/expression of recognition memory. In a series of four experiments, effects on encoding versus retrieval/expression were examined after both short (20 min) retention delays similar to those used in previous lesion studies and a longer $(24 \mathrm{~h})$ delay more similar to those used in the electrophysiological studies which have indicated a role for ACgx in NOR. 
Table 1. Effect of ACgx microinfusion of muscimol on total exploration

\begin{tabular}{|c|c|c|c|c|}
\hline Infusions & Delay & Sal & $\begin{array}{l}62.5 \mathrm{ng} / \\
\text { side }\end{array}$ & $\begin{array}{l}125 \mathrm{ng} / \\
\text { side }\end{array}$ \\
\hline $\begin{array}{l}\text { In ACgx before } \\
\text { encoding }\end{array}$ & $20 \mathrm{~min}$ & $\begin{array}{l}\text { a } 54.9 \pm 5.7 \\
\text { b } 32.2 \pm 5.1\end{array}$ & $\begin{array}{l}56.8 \pm 7.7 \\
31.7 \pm 5.8\end{array}$ & $\begin{array}{l}44.0 \pm 6.8 \\
26.4 \pm 4.5\end{array}$ \\
\hline $\begin{array}{c}\text { In ACgx before } \\
\text { retrieval }\end{array}$ & $20 \mathrm{~min}$ & $\begin{array}{l}\text { a } 79.6 \pm 6.5 \\
\text { b } 39.0 \pm 6.3\end{array}$ & $\begin{array}{l}66.9 \pm 5.9 \\
32.1 \pm 2.9\end{array}$ & $\begin{array}{l}73.7 \pm 8.5 \\
28.7 \pm 3.6\end{array}$ \\
\hline $\begin{array}{l}\text { In ACgx before } \\
\text { encoding }\end{array}$ & $24 \mathrm{~h}$ & $\begin{array}{l}\text { a } 80.5 \pm 8.7 \\
\text { b } 47.4 \pm 3.5\end{array}$ & $\begin{array}{l}52.4 \pm 6.7 \\
49.2 \pm 4.9\end{array}$ & $\begin{array}{l}70.8 \pm 13.3 \\
54.8 \pm 4.3\end{array}$ \\
\hline $\begin{array}{l}\text { In ACgx before } \\
\text { retrieval }\end{array}$ & $24 \mathrm{~h}$ & $\begin{array}{l}\text { a } 73.0 \pm 7.3 \\
\text { b } 38.6 \pm 3.2\end{array}$ & $\begin{array}{l}67.0 \pm 5.1 \\
35.6 \pm 3.7\end{array}$ & $\begin{array}{l}68.1 \pm 4.9 \\
30.6 \pm 4.1\end{array}$ \\
\hline
\end{tabular}

Time in seconds (mean \pm SEM) of both objects, during the sample (a), and choice (b) phases of the NOR task for each of experiments 1-4.

\section{Results}

Experiment 1: ACgx infusion of muscimol before the encoding phase does not affect NOR assessed after a delay of $20 \mathrm{~min}$

ANOVA confirmed that muscimol infusion into the ACgx did not alter the total exploration of objects during the sample phase $\left(F_{(2,18)}=1.418 ; P=0.268\right)$ (Table 1 ; Fig. 1A for timeline).

Although ANOVA showed no three-way interaction of treatment $\times$ object $\times 1$-min block $(F(4,36)=0.243 ; P=0.912)$, the minute-by-minute change in object exploration over the 3 min of the choice trial was significant (two-way interaction of object $\times 1$-min block: $\left.F_{(2,18)}=7.170 ; P=0.0051\right)$. Inspection of the means confirmed that rats preferentially explored the novel object during the first minute of testing. This preference for the novel object was clearly present at both doses of muscimol infused on the first 1-min block of testing (Fig. 1B). Follow-up ANOVA of exploration time during the first 1-min block yielded a main effect of object $\left(F_{(1,9)}=22.807 ; P=0.001\right)$ but no object $\times$ drug interaction $\left(F_{(2,18)}=0.396 ; P=0.678\right)$ or main effect of drug $\left(F_{(2,18)}=2.359 ; P=0.123\right)$.

The discrimination ratios confirmed that rats preferentially explored the novel over the familiar object independent of drug treatment (Fig. 1C). One-way ANOVA showed that the discrimination ratios during the first $1 \mathrm{~min}$ of testing were equivalent in the different drug treatment conditions $\left(F_{(2,18)}=0.109\right.$; $P=0.897)$. Performance differed from chance in the saline condition $\left(t_{(9)}=2.954 ; P=0.016\right)$, and after receiving an infusion of $62.5 \mathrm{ng} /$ side $\left(t_{(9)}=3.460 ; P=0.007\right)$ of muscimol. The group receiving $125 \mathrm{ng}$ /side of muscimol did not differ from chance on the discrimination ratio measure $\left(t_{(9)}=1.796 ; P=0.106\right)$. However, since there was no overall effect of drug and in this condition too the discrimination ratio was above chance, the results overall suggest that infusion of muscimol into the ACgx cortex before the encoding of NOR does not impair the ability of the rats to discriminate novel from familiar objects using a choice delay of $20 \mathrm{~min}$.

\section{Experiment 2: ACgx infusion of muscimol before the retrieval phase does not affect NOR assessed after a delay of $20 \mathrm{~min}$}

The total exploration of both objects during the sample phase was unaffected by infusion of muscimol into the $\operatorname{ACgx}\left(F_{(2,22)}=1.704\right.$; $P=0.205$ ) (Table 1; Fig. 2A for timeline).

The exploration profile of the novel versus familiar object changed during the 3 min test as indicated by a two-way interaction of object $\times 1$-min block $\left(F_{(2,22)}=7.380 ; P=0.003\right)$. Examination of the means confirmed that the expected difference in object exploration was mainly present during the first minute of the test session when all groups preferentially explored the novel object (Fig. 2A). This is confirmed by a main effect of object $\left(F_{(1,11)}=22.741 ; P=0.0006\right)$ and a lack of interaction between object and drug $\left(F_{(2,22)}=0.383 ; P=0.685\right)$ or any main effect of $\operatorname{drug}\left(F_{(2,22)}=0.712 ; P=0.501\right)$.

The equivalent discrimination ratios confirm that rats preferentially explore the novel more than the familiar object independent of treatment (Fig. 2C). The discrimination ratios during the $1 \mathrm{~min}$ of testing were equivalent across the treatment conditions $\left(F_{(2,22)}=0.460 ; P=0.637\right)$. Moreover, the one sample $t$-tests confirm that the discrimination ratios in all groups were different from chance $(0.5)$ : saline $\left(t_{(11)}=4.644 ; P=0.0007\right)$; muscimol $62.5 \mathrm{ng} /$ side $\left(t_{(11)}=2.803 ; P=0.017\right) ;$ muscimol $125 \mathrm{ng} /$ side $\left(t_{(11)}=2.44 ; P=0.029\right)$. Thus, these data show that infusion of
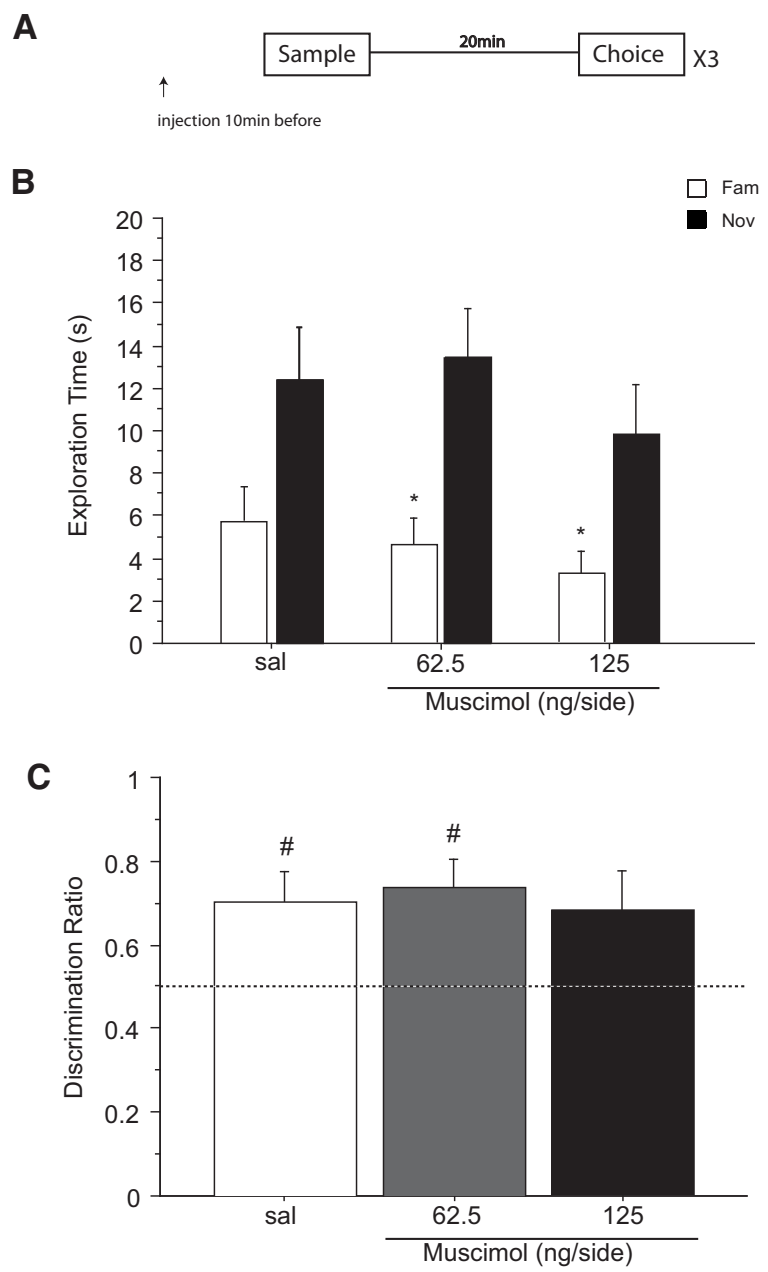

Figure 1. Effect of saline (sal) or muscimol (62.5 and $125 \mathrm{ng}$ per side) infused into the anterior cingulate cortex before the sample phase on novel object recognition after a retention delay of $20 \mathrm{~min} . N=10$ rats in total. (A) Timeline of experiment 1 to illustrate the 20 -min retention delay between the sample and the choice phase, the timing of the infusions 10 min before the sample phase and the repeated $(\times 3)$ testing in the within-subjects design. $(B)$ Effect of muscimol on the first minute exploration time (sec, mean \pm SEM) of a novel (Nov) and a familiar (Fam) object during the choice phase. $\left(^{*}\right) P<0.05$, significant difference when compared with the familiar object. (C) Choice performance presented as the discrimination ratio during the first minute of exploration (mean \pm SEM); stippled line indicates chance. (\#) $P<0.05$, significantly different from chance. 
A
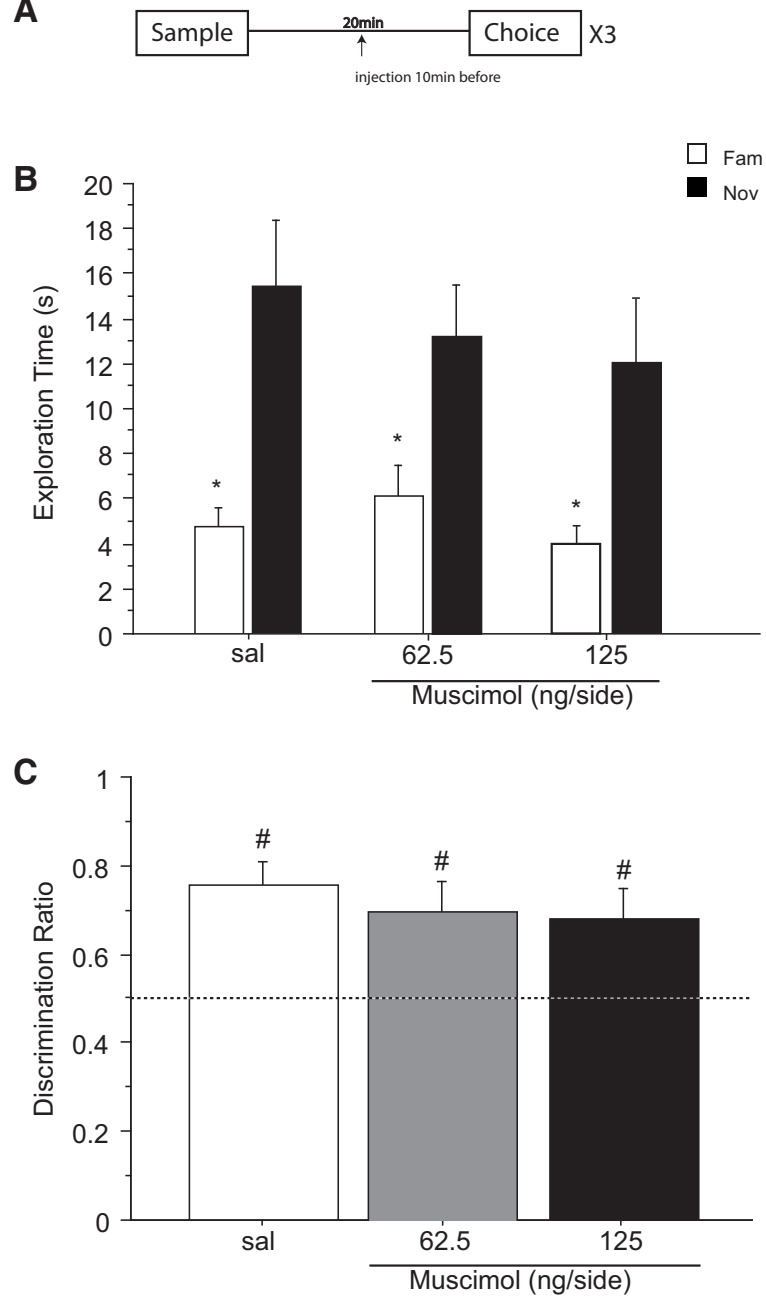

Figure 2. Effect of saline (sal) or muscimol (62.5 and $125 \mathrm{ng} /$ side) infused into the cingulate cortex before the choice phase on novel object recognition after a retention delay of $20 \mathrm{~min} . \mathrm{N}=12$ rats in total. (A) Timeline of experiment 2 to illustrate the 20 -min retention delay between the sample and the choice phase, the timing of the infusions $10 \mathrm{~min}$ before the choice phase and the repeated $(\times 3)$ testing in the within-subjects design. $(B)$ Effect of muscimol on the first minute of exploration time (sec, mean \pm SEM) of a novel (Nov) and a familiar (Fam) object during the choice phase. $\left(^{*}\right) P<0.05$, significant difference when compared with the familiar object. (C) Choice performance presented as the discrimination ratio during the first minute of exploration (mean \pm SEM); stippled line indicates chance. (\#) $P<0.05$, significantly different from chance.

muscimol into the ACgx cortex before the retrieval of NOR does not impair the ability of the rats to discriminate novel from familiar objects using a choice test delay of $20 \mathrm{~min}$.

\section{Experiment 3: ACgx infusion of muscimol before the encoding phase does not affect NOR assessed after a delay of $24 \mathrm{~h}$}

Again, ANOVA showed that muscimol infusion into the ACgx, did not alter the total exploration of objects presented during the sample phase $\left(F_{(2,12)}=1.920 ; P=0.189\right)$ (Table 1 ; Fig. 3A for timeline).

While the three-way interaction treatment $\times$ object $\times 1$-min block failed to reach significance $\left(F_{(4,40)}=1.067 ; P=0.385\right)$, a minute-by-minute change in object exploration over the 3-min choice trial was significant (two-way interaction of object $x$ 1-min block: $\left.F_{(2,20)}=5.516 ; P=0.012\right)$. As in the previous experiments, this arose because animals preferentially explored the novel object during the first 1-min block of testing at both doses of muscimol as well as under saline (Fig. 3B). Similarly, ANOVA of exploration time during the first 1-min block yielded a main effect of object $\left(F_{(1,10)}=30.237 ; P=0.0003\right)$ but no object $\times$ drug interaction $\left(F_{(2,20)}=0.238 ; P=0.790\right)$ or main effect of drug $\left(F_{(2,20)}=2.549 ; P=0.103\right)$.

One-way ANOVA showed that the discrimination ratios during the 1-min of testing were not different between treatment conditions $\left(F_{(2,20)}=1.535 ; \quad P=0.239\right)$. All rats preferentially

A

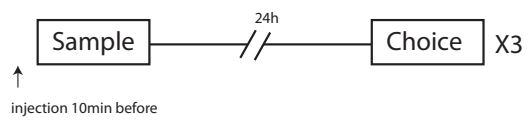

B
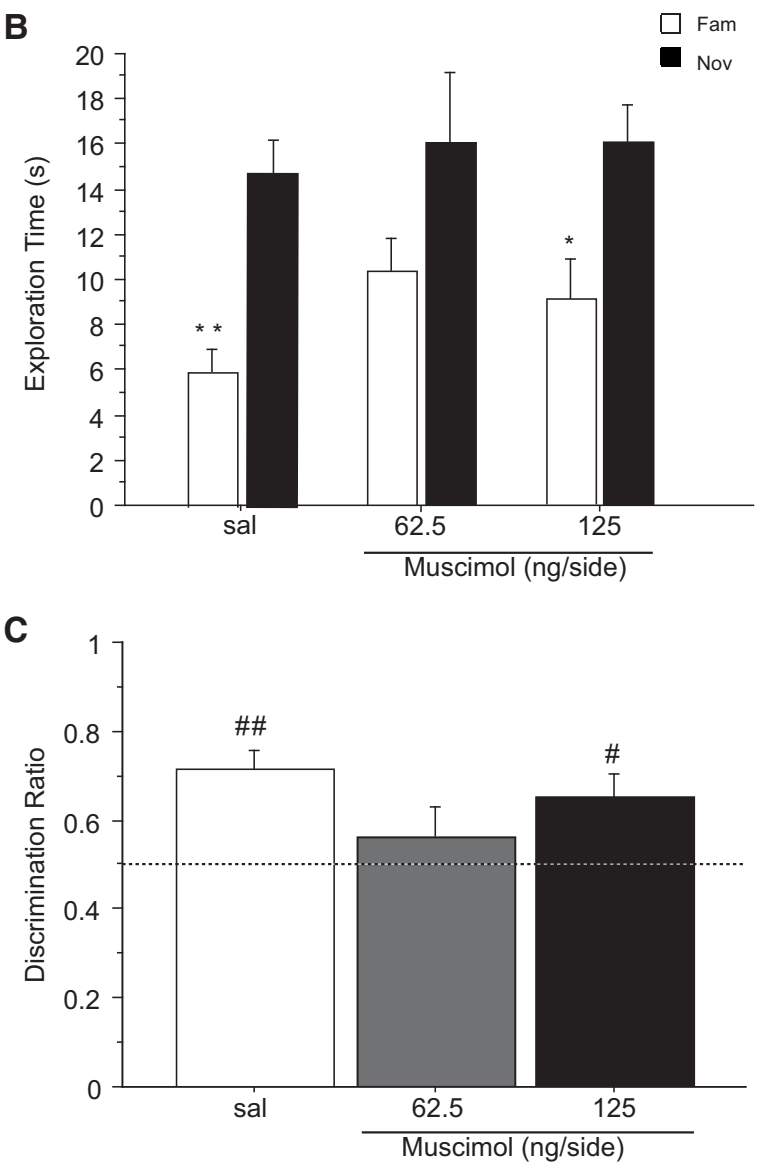

Figure 3. Effect of saline (sal) or muscimol (62.5 and $125 \mathrm{ng} / \mathrm{side}$ ) infused into the cingulate cortex before the sample phase on novel object recognition after a retention delay of $24 \mathrm{~h} . N=11$ rats in total. (A) Timeline of experiment 3 to illustrate the $24-\mathrm{h}$ retention delay between the sample and the choice phase, the timing of the infusions $10 \mathrm{~min}$ before the sample phase and the repeated $(\times 3)$ testing in the within-subjects design. (B) Effect of muscimol on the first minute of exploration time (sec, mean \pm SEM) of a novel (Nov) and a familiar (Fam) object during the choice phase. $\left({ }^{*}\right) P<0.05,\left({ }^{* *}\right) P<0.001$, significant difference when compared with the familiar object. $(C)$ Choice performance presented as the discrimination ratio during the first minute of exploration (mean \pm SEM); stippled line indicates chance. (\#) $P<0.05$, (\#\#) $P<$ 0.001 , significantly different from chance. 
explored the novel over the familiar object independently of their treatment (Fig. 3C). Performance differed from chance in the saline condition $\left(t_{(10)}=5.043 ; P=0.001\right)$, and after receiving an infusion of $125 \mathrm{ng} / \mathrm{side}\left(t_{(10)}=2.730 ; P=0.021\right)$ of muscimol. Rats receiving $62.5 \mathrm{ng} /$ side of muscimol were not different from chance $\left(t_{(10)}=0.916 ; P=0.381\right)$. However, taken together, these data do not provide convincing evidence that infusion of muscimol into the ACgx cortex before encoding impairs the ability of the rats to discriminate the novel object following a trial delay of $24 \mathrm{~h}$.

\section{Experiment 4: ACgx infusions of muscimol before the retrieval phase reduce NOR assessed after a delay of $24 \mathrm{~h}$} ANOVA showed that the total exploration of both objects during the sample phase was similar for all doses $\left(F_{(2,18)}=0.407\right.$; $P=0.671$ ) (Table 1; Fig. 4A for timeline).

A minute-by-minute change in object exploration over the 3 -min test period of the choice trial was revealed by a three-way interaction of treatment $\times$ object $\times 1$-min block $\left(F_{(4,36)}=3.641\right.$; $P=0.013)$. Inspection of the means shows that the effect of muscimol was due to a decrease in the time spent exploring the novel object during the first minute of the choice trial (Fig. 4B). ANOVA of exploration time during the first 1-min block yielded an effect of object $\times$ treatment $\left(F_{(1,9)}=5.581 ; P=0.042\right)$. This interaction was however not significant during the second and third 1-min blocks (maximum $F_{(1,9)}=0.668 ; P=0.435$ ) confirming that the effect was confined to the first minute only.

Follow-up analysis of the time spent exploring the novel object during the first 1-min block also showed a marginal effect of drug $\left(F_{(2,18)}=3.470 ; P=0.053\right)$. This arose because of decreased novel object exploration compared with saline after high doses of muscimol (sal versus $125 \mathrm{ng} /$ side; $P=0.021$ ). There was no significant effect of drug on familiar object exploration $\left(F_{(2,18)}=\right.$ $1.441 ; P=0.262$ ). Furthermore, planned comparisons (by paired $t$-test) showed that the exploration time during the first 1-min block was significantly higher for the novel object than for the familiar one in the saline condition $\left(t_{(9)}=2.565 ; P=0.030\right)$, but not after injection of $62.5 \mathrm{ng} /$ side $\left(t_{(9)}=2.012 ; P=0.075\right)$ and $125 \mathrm{ng} /$ side $\left(t_{(9)}=0.445 ; P=0.667\right)$ of muscimol (Fig. 4B).

It was also clear from the discrimination ratio that during the first 1-min block the drug groups differed markedly in the proportion of time spent exploring the two objects (Fig. 4C). ANOVA of the 1-min discrimination ratio confirm a significant main effect of muscimol $\left(F_{(1,9)}=5.249 ; P=0.048\right)$. Post hoc comparisons indicated that the higher $(P=0.020)$, but not the lower dose $(P=0.201)$ of muscimol decreased recognition of the novel object compared with saline. This was also confirmed by one sample $t$-test comparing the discrimination ratio in each treatment condition to chance (0.5). Performance differed from chance after saline $\left(t_{(9)}=3.446 ; P=0.007\right)$ but not after infusions of $62.5 \mathrm{ng} /$ side $\left(t_{(9)}=1.767 ; P=0.111\right)$ or $125 \mathrm{ng} /$ side $\left(t_{(9)}=0.438 ; P=0.671\right)$ of muscimol.

Thus, these data show that infusion of muscimol into the ACgx cortex before the retrieval of NOR impaired the ability of the rats to discriminate novel from familiar object using a choice test delay of $24 \mathrm{~h}$.

\section{Discussion}

The results of the present series of experiments point to the importance of the interval between sample and retention testing as well as the stage of the learning task at which ACgx was inactivated. Specifically, the present study shows that ACgx infusions of muscimol before encoding did not alter NOR assessed at a retention delay of $20 \mathrm{~min}$ or $24 \mathrm{~h}$. When infused into the ACgx before re-
A
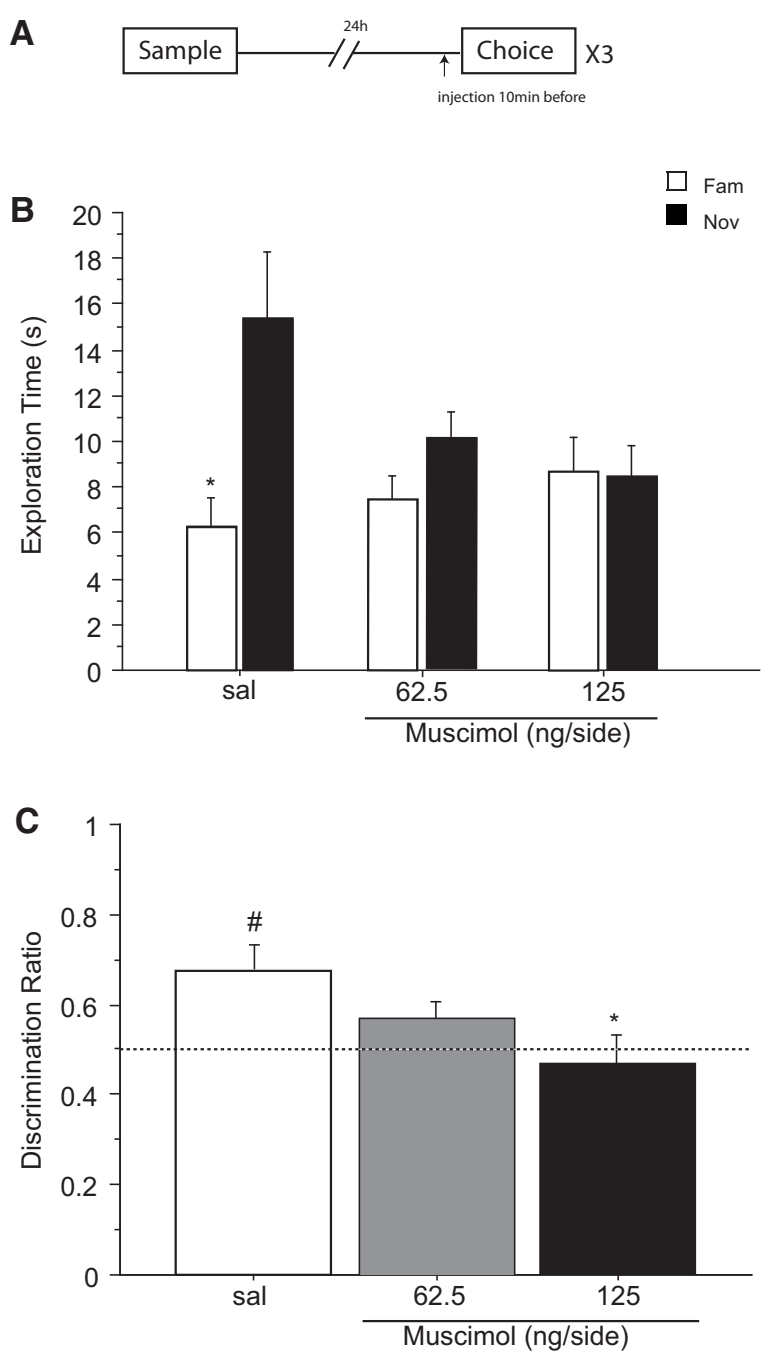

Figure 4. Effect of saline (sal) or muscimol (62.5 and $125 \mathrm{ng} / \mathrm{side}$ ) infused into the cingulate cortex before the choice phase on novel object recognition after a retention delay of $24 \mathrm{~h} . N=10$ rats in total. $(A)$ Timeline of experiment 4 to illustrate the $24 \mathrm{~h}$ retention delay between the sample and the choice phase, the timing of the infusions $10 \mathrm{~min}$ before the choice phase and the repeated $(\times 3)$ testing in the withinsubjects design. (B) Effect of muscimol on the first minute of exploration time (sec, mean \pm SEM) of a novel (Nov) and a familiar (Fam) object during the choice phase. $\left({ }^{*}\right) P<0.05$, significant difference when compared with the familiar object. $(C)$ Choice performance presented as the discrimination ratio during the first minute of exploration (mean \pm SEM); stippled line indicates chance. $\left(^{*}\right) P<0.05$, significantly different from the saline condition; (\#) $P<0.05$, significantly different from chance.

trieval however, muscimol reduced NOR, assessed after a delay of $24 \mathrm{~h}$ but not $20 \mathrm{~min}$. Taken together, these findings suggest that the ACgx plays a retention delay-dependent role in the retrieval, but not the encoding, of NOR memory, contributing to the retrieval of remote $(24 \mathrm{~h}$ old $)$, but not recent $(20 \mathrm{~min}$ old $)$ NOR memory.

Infusion sites were located in the anterior subdivisions of the cingulate cortex. With the small infusion volume $(0.5 \mu \mathrm{L} /$ side $)$ and fine infusion cannulae (26 gauge) used in the present study, the estimated spread of the infused substances was $<1 \mathrm{~mm}$ (Myers et al. 1971; Routtenberg 1972; Bast and Feldon 2003). It is, therefore, likely that differences between drug conditions (demonstrated within subjects) can be attributed to the temporary 
alteration of neuronal activity by stimulation of $\mathrm{GABA}_{\mathrm{A}}$ receptors within the ACgx. In experiment 4, the two doses of muscimol infused (62.5 and $125 \mathrm{ng} /$ side) produced a similar outcome. Both doses abolished the preferential time spent exploring the novel object. This similarity suggests that even the lower dose was sufficient to produce high occupancy of $\mathrm{GABA}_{\mathrm{A}}$ receptors. It would, therefore, be of interest to investigate the effect of lower doses of muscimol infused in the ACgx, to determine whether a dose-related effect can be demonstrated.

As outlined in the Introduction, temporary regional brain inactivation may reveal some regional functions that have eluded lesion studies (Majchrzak and Di Scala 2000). Permanent brain lesions may fail to reveal normal behavioral contributions of the lesioned regions, because, following complete and permanent loss of hippocampal output, other brain regions may mediate these processes or because deficits could be masked by lesioninduced distal changes (cf. Bast and Feldon 2003; Wang et al. 2015). In addition, brain lesions are irreversible and, therefore, make it impossible to dissociate between the different stages of memory: encoding, storage, consolidation, and retrieval. As opposed to previous aspiration (Meunier et al. 1997) and electrolytic (Ennaceur et al. 1997) lesions, in the present study we have used the $\mathrm{GABA}_{\mathrm{A}}$ receptor agonist muscimol to temporarily inactivate the ACgx. As a result we have successfully shown that the ACgx plays a critical role in the expression/retrieval but not the encoding of a remote NOR memory.

In our study, the encoding and retrieval of short-term NOR memory (20 min delay) were not impaired by ACgx inhibition. This is consistent with other studies in which monkeys and rats were tested only shortly after the sample phase ( 15 min maximum) and lesions of the ACgx had no effect on NOR (Ennaceur et al. 1997; Meunier et al. 1997). It is also consistent with another inactivation study where PL/ACgx infusion of lidocaine before encoding failed to impair a 105-min-old NOR memory (Hannesson et al. 2004b). Together, this suggests that short-term NOR memory does not require the ACgx. However, the present study shows that ACgx inhibition before retrieval, but not encoding, abolished long-term (24 h) NOR memory. Thus, previous conventional lesion studies may have failed to reveal a role for ACgx because of the use of a short retention test interval and their inability to address the distinction between encoding and retrieval/expression.

In contrast, the findings of the present study are consistent with several electrophysiological studies, which have reported a neuronal correlate during the retrieval of remote NOR memory in the ACgx of adult monkeys and rats (Rainer and Miller 2000; Xiang and Brown 2004). In these studies, recordings of neural activity within ACgx were carried out during retrieval of NOR memory following a retention delay of more than $24 \mathrm{~h}$ after encoding. Interestingly, using early-gene activation techniques, Barbosa and co-workers analysed the correlation between cognitive demand in object recognition variants (discrimination between novel and familiar object and spatiotemporal discrimination of familiar object) and activation of the mPFC including the ACgx. They found that the number of c-Fos and Zif-268-positive neurons in the mPFC was significantly increased compared with the control condition after retrieval of a NOR task (Barbosa et al. 2013). These data suggest that activity within the mPFC is associated with successful retrieval of NOR. Together with the findings of the present study, the above data suggest that the ACgx may be necessary for the retrieval of NOR after a delay longer than 24 h. However, the fact that we found retrieval was unimpaired at the 20-min retention delay used in experiment 2 further suggests that a general retrieval impairment cannot be a full account of the present set of findings. Moreover, apparent difficulties with 24-h delay retrieval could be secondary to impaired consolidation processes known to take place in $\mathrm{mPFC}$.
Akirav and Maroun (2006) have demonstrated that injection of the protein synthesis inhibitor anisomycin into the mPFC immediately after training similarly resulted in the impairment of long-term ( $24 \mathrm{~h}$ ), but not short-term memory (in this case $3 \mathrm{~h}$ ). These results indicate that the $\mathrm{mPFC}$ is required for consolidation of early into long-term $(24 \mathrm{~h})$ NOR memory. Furthermore, Romero-Granados et al. (2010) showed Zif-268 and also BDNF expression in the $\mathrm{mPFC}$ following reactivation of NOR. Interestingly, a recent electrophysiological study in mice also supports a role of ACgx in consolidation of object/place recognition memory by showing that the ACgx neurons respond-when tested even 1 mo later-to the place where an object has previously been positioned (Weible et al. 2012). The present study shows that ACgx functional inhibition impaired the retrieval of long-term $(24 \mathrm{~h})$, but not short term (20 min) NOR memory. This suggests that, following the $24 \mathrm{~h}$ delay information underlying NOR retrieval was present in the ACgx, which, in line with the findings reviewed above, shows that the NOR information may have been consolidated into the ACgx. As mentioned above, one function of the mPFC is to consolidate NOR memory, and the role of dopamine in the consolidation of long-term memory has recently been investigated by Rossato et al. (2013). They infused the D1 receptor antagonist SCH13390 into the mPFC just after the encoding of a NOR task and found that such a manipulation affected consolidation. They also found that the deficit observed by blocking the VTA could be rescued by infusing the D1 receptor agonist SKF38397 into the mPFC. By using a similar microinjection approach in the mPFC we have also shown that blockade of dopamine $D_{3}$ receptors enhances, while $D_{3}$ receptor activation or antagonism of dopamine $\mathrm{D}_{2}$ receptors impairs NOR in the rat (Watson et al. 2012). Taken together these findings, which demonstrate the importance of dopamine neurotransmission in the mPFC for NOR consolidation, are also consistent with our findings. In future experiments, we plan to further examine the role of dopamine in the retrieval of long-term NOR memory, tested also in other variants to examine memory for relative recency and object location (Nelson et al. 2011).

Although the present data show that the ACgx is required for the retrieval of remote NOR at a 24 -h retention delay, clearly other brain regions, particularly the perirhinal cortex play a key role both retrieval and consolidation of NOR memory (Winters and Bussey 2005a,b; Dere et al. 2007; Winters et al. 2008; Brown et al. 2010; Warburton and Brown 2010). There are direct reciprocal connections between the perirhinal cortex and the mPFC including the ACgx (Sesack et al. 1989; Lavenex et al. 2002; Jones and Witter 2007). It is, therefore, possible that these projections from the perirhinal cortex underlie the expression/retrieval of remote $(24 \mathrm{~h}$ old) NOR memory, which is dependent on ACgx activity.

While there is a general consensus that the perirhinal cortex is required for encoding, storage, consolidation, and retrieval of NOR memory (Winters et al. 2008), there is also evidence that NOR memory may depend on the hippocampus, specifically when the retention interval between encoding and retrieval is long (24 h) (Clark et al. 2000; Baker and Kim 2002; Hammond et al. 2004). Also, more recent findings have provided strong evidence that hippocampo-prefrontal interactions underlie consolidation of spatial and contextual fear memories (Frankland and Bontempi 2005; Squire and Bayley 2007). It is, therefore, tempting to speculate that a hippocampo-prefrontal consolidation process may also contribute to remote NOR memory becoming dependent on the ACgx, as suggested by our present study. Thus, the findings of the present study could have broader implications for the role of ACgx in memory processes.

Based on the pattern of results in the present study, the ACgx seems to play a role in the expression/retrieval of remote $(24 \mathrm{~h}$ 
old) NOR memory. This effect may have been masked in previous study by the use of lesion as opposed to inactivation (also compare Wang et al. 2015) and by the testing of recent NOR memory $(<15$ min) only (Ennaceur et al. 1997; Meunier et al. 1997). We propose that the results of the present study may be explained if NOR memory is either consolidated in the ACgx directly or via perirhinal-ACgx interactions, both of which could lead to remote NOR memory becoming dependent on the ACgx.

\section{Materials and Methods}

\section{Animals}

Adult male Wistar rats (Charles River, UK) were housed in groups of four in individually ventilated cages on a 12:12 h light-dark cycle (lights on $07.00 \mathrm{~h}$ ) with food and water available ad libitum. Rats were handled for approximately $10 \mathrm{~min}$ per day for $1 \mathrm{wk}$ prior to any procedure. All procedures were carried out in accordance with the United Kingdom (UK) Animals Scientific Procedures Act 1986, in accordance with the ARRIVE guidelines and with University of Nottingham Ethical Committee approval. In total 48 non-naive rats (previously conditioned and infused once) were used ( $n=12$ /experiment; mean weight immediately before the NOR experiments $417 \mathrm{~g}$; operated in the range 245-304 g). In experiments 1 and 4 two rats were humanely killed (and, therefore, not included in the analysis) because of poor recovery post-surgery. In each of experiments 1,3 , and 4 , one rat (in total three across the series of experiments) was also excluded from the analysis because the injector tip was located in the prelimbic mPFC.

\section{Implantation of guide cannulae into the mPFC}

These methods were identical for each of the four experiments. Perioperative analgesia was also administered (Rimadyl large animal solution, 1:9 dilution in saline at $0.2 \mathrm{~mL} / 250 \mathrm{~g}$ s.c.). Rats were anesthetized using isoflurane delivered in oxygen (induction: $4 \%-5 \%$; maintenance: $1 \%-3 \%$ ) before being secured in a stereotaxic frame. The skull was exposed and bregma and lambda were aligned horizontally. A bilateral infusion guide cannula (model C235GS-5-1.2 Plastic Ones, Bilaney) consisting of a 5-mm plastic pedestal holding two 26 gauge metal tubes $(1.2 \mathrm{~mm}$ apart and projecting $4.5 \mathrm{~mm}$ from the pedestal) was implanted through small holes drilled in the skull. The tips of the guide cannula were implanted $0.5 \mathrm{~mm}$ above the injection site in the ACgx part of the prefrontal cortex, at the following coordinates: $\pm 1.9 \mathrm{~mm}$ anterior and $\pm 0.6 \mathrm{~mm}$ lateral from bregma, and $-2.3 \mathrm{~mm}$ ventral from the skull surface (Paxinos and Watson 1998) adapted from a previous study (Schweimer and Hauber 2006; Einarsson and Nader 2012) on the basis of pilot surgery. The cannula was secured to the skull with dental acrylic around stainless steel screws. Double stylets (33 gauge; Plastic Ones, Bilaney) were inserted into the guides (with no protrusion), which was closed with a dust cap. Following surgery, rats were allowed at least $5 \mathrm{~d}$ recovery before any testing commenced. During the recovery period, rats were checked daily and habituated to the manual restraint necessary for the drug microinjection. Rats received antibiotics (Synulax, $0.01 \mathrm{~mL} / 200 \mathrm{~g}$ s.c.) $24 \mathrm{~h}$ prior to surgery and daily thereafter until the end of the study.

\section{Microinjection procedure}

Rats were gently restrained and 33 gauge injectors (Plastic Ones, Bilaney) inserted into the guides such that tips extended $0.5 \mathrm{~mm}$ into the mPFC, and the injector ends were connected through polyethylene tubing to $5 \mu \mathrm{L}$ syringes mounted on a microinfusion pump (model SP200iZ, World Precision Instruments). A volume of $0.5 \mu \mathrm{L} /$ side of $0.154 \mathrm{M}$ saline or muscimol (62.5 or $125 \mathrm{ng} / \mathrm{side}$ ) was then infused bilaterally over $1 \mathrm{~min}$. The movement of an air bubble, which was included in the tubing, was monitored to verify that treatments were successfully infused into the brain. The injector remained in place for one additional minute to allow for tissue absorption of the infusion bolus. The injectors were then removed and the stylets replaced. The choice or test phase of NOR commenced $10 \mathrm{~min}$ after infusion. Muscimol was dissolved in saline at a concentration of $125 \mathrm{ng} / 0.5 \mu \mathrm{L}$. This solution was aliquoted and kept frozen until use. On the day of infusion an aliquot was thawed and a part of this solution was diluted to a concentration of $62.5 \mathrm{ng} / 0.5 \mu \mathrm{L}$ with saline.

\section{NOR: behavioral apparatus}

All testing was conducted in a $38 \times 40-\mathrm{cm}$ opaque plastic rectangular arena with $54-\mathrm{cm}$ high walls. An overhead camera was used to record behavior for subsequent analysis. The stimuli consisted of duplicate copies of bottles and flasks made of glass, metal or plastic of varied shape, color and size, which were too heavy to be displaced by the rat. During the sampling phase, two similar objects were placed in opposite corners of the arena. The sets of two objects used during the sampling phase differed markedly and did not appear to share common features. The particular set of objects selected was counterbalanced across tests, as was their placement (left or right of arena). The familiar object at test was always an identical copy of the object seen at sampling. Time spent exploring each object was defined as directing the nose at the object at a distance of $<1 \mathrm{~cm}$ and actively exploring it (i.e., sniffing and/or interacting with the object). Object exploration was not scored if the animal was in contact with but not facing the object or if it sat on the object or used it as a prop (Ennaceur and Delacour 1988). The test box and objects were cleaned with an alcohol-based solution $(20 \% \mathrm{v} / \mathrm{v})$ before each trial to remove odor cues. The rats' behavior was recorded for later analysis. Videos recorded on experimental days were reanalysed and time spent exploring each object during either the sampling or the choice phase were quantified using a stop watch.

\section{NOR: behavioral procedure}

The NOR task was based on previously established protocol (Pezze et al. 2015). Experiments 1 and 2 were run over a $6 \mathrm{~d}$ cycle in a within-subjects design. On days 1,3 , and 5 rats were placed individually into the arena for $1 \mathrm{~h}$. In experiment 1 , on days 2 , 4 , and 6 , rats underwent a reacclimatization of $3 \mathrm{~min}$ to the arena before receiving one of three bilateral ACgx infusions $10 \mathrm{~min}$ before the sampling phase: saline, $125 \mathrm{ng}$ (62.5 ng/side), $250 \mathrm{ng}$ (125 ng/side) of the $\mathrm{GABA}_{\mathrm{A}}$ receptor agonist muscimol. After a delay of $20 \mathrm{~min}$, during which the rat was returned to their home cage, each rat was tested for $3 \mathrm{~min}$ in the arena containing a novel object and an identical copy of the object previously seen during the sampling phase (Fig. 1A). In experiment 2 rats also underwent a reacclimatization on days 2,4 , and 6 before the sampling phase. They then were infused with one of the three doses of muscimol 10 min before the choice phase during the 20-min delay. Rats were next tested for $3 \mathrm{~min}$ as described above (Fig. 2A). Experiments 3 and 4 were run over a 9-d cycle in a within-subjects design. On days 1,4 , and 7 rats were placed individually into the arena for $1 \mathrm{~h}$. In experiment 3 , on day 2, 5 and 8 rats underwent a reacclimatization of $3 \mathrm{~min}$ to the arena before receiving one of three bilateral $\mathrm{mPFC}$ infusions $10 \mathrm{~min}$ before the sampling phase: saline, $125 \mathrm{ng}$ (62.5 ng/side), $250 \mathrm{ng}$ (125 ng/side) of the GABA receptor agonist muscimol. After a delay of $24 \mathrm{~h}$ in which the rats were returned to their home cage, each rat was tested on day 3,6 , 9 , for $3 \mathrm{~min}$ in the arena containing a novel object and an identical copy of the object previously seen during the sampling phase (Fig. 3A). In experiment 4 , on day 2, 5, and 8 rats also underwent a reacclimatization of $3 \mathrm{~min}$ to the arena before the sample phase. Rats were infused on day 3, 6, 9 with one of the three doses of muscimol $10 \mathrm{~min}$ before the choice phase and after a delay of $24 \mathrm{~h}$. In all experiments, the order of the three infusions was counterbalanced using a Latin square design. During the 5-min sampling period the rats were exposed to two identical objects. After a delay of $20 \mathrm{~min}$ or $24 \mathrm{~h}$ in which the rats were returned to their home cage, each rat was tested for $3 \mathrm{~min}$ in the arena containing a novel object and an identical copy of the object previously seen during the sampling phase. Again, the time spent exploring the 
familiar and novel object was recorded. In the course of the three sampling/choice sessions, three different object pairs were used, counterbalanced across the infusions conditions. The present study used Wistar rats that have relatively poor visual acuity (compared with strains having pigmented iris) and, therefore, may have used nonvisual attributes of the objects (such as texture) to discriminate them. As objects were cleaned with ethanol after each trial it is unlikely that olfactory cues could have been utilized for the discriminations.

\section{Inter-rater reliability}

An independent experimenter who was blind to the treatment and object contingencies rescored $20 \%$ of all test phases from the original video recording. The rescored results significantly correlated with the original scores $(r=0.84, P<0.001)$ indicating robust inter-rater reliability.

Verification of cannulae placements for behavioral studies Following the completion of the experiments, rats were anesthetized with sodium pentobarbitone (1-1.5 mL Euthatal; sodium pentobarbitone, $200 \mathrm{mg} / \mathrm{mL}$; Genus Express, UK) and perfused transcardially with $0.9 \%$ saline followed by $4 \%$ formaldehyde solution in saline. Brains were removed from the skull, post-fixed in $4 \%$ formaldehyde, and cut into $80 \mu \mathrm{m}$ coronal sections on a vibratome and sections containing PFC were mounted on slides and stained with cresyl violet. Placements of the injector were determined using a light microscope and mapped onto coronal sections of a rat brain stereotaxic atlas (Paxinos and Watson 1998; Fig. 5).

\section{Design and analysis}

The results are shown as means $( \pm \mathrm{SEM}) ; P$ values of $<0.05$ are considered to indicate statistical significance.

\section{Exploration time}

In all experiments, the results obtained using the Latin square procedure were analysed in an entirely within-subjects design, object (novel versus familiar) was a within-subjects factor as was 1-min block (at three levels). Thus, this design examines minute-by-minute variation in NOR over the duration of the test session. Treatment with muscimol was also within-subjects (at three levels). All rats were administered saline, $125 \mathrm{ng}$ muscimol (62.5 ng/side) and $250 \mathrm{ng}$ muscimol (125 ng/side) in a counterbalanced order. ANOVAs showed marked variation in NOR over the 3-min test session (as reflected in significant interactions between object and 1-min block). Where ANOVA showed such interactions, separate follow-up analyses of the familiar or novel object exploration time were performed using treatment as the only factor. Since all experiments showed clear NOR in the first minute of the test, the follow-up analyses, conducted to exclude the possibility of any muscimol effect, were restricted to minute 1 of the choice trial (see also Pezze et al. 2015). Further post hoc pairwise comparisons were performed using Fisher's PLSD. One sample $t$-tests were also used as planned comparisons to compare the novel versus familiar object exploration time.

\section{Discrimination ratio}

The time spent exploring the novel object divided by the total time spent exploring both objects during the choice phase was calculated for the first minute of exploration. Drug treatment was a within-subject factor. Treatment differences shown by the ANOVA were further analysed using Fisher's PLSD test. One sample $t$-tests were used as planned comparisons to compare performance measures to the 0.5 value of the ratio, which reflects chance level performance.

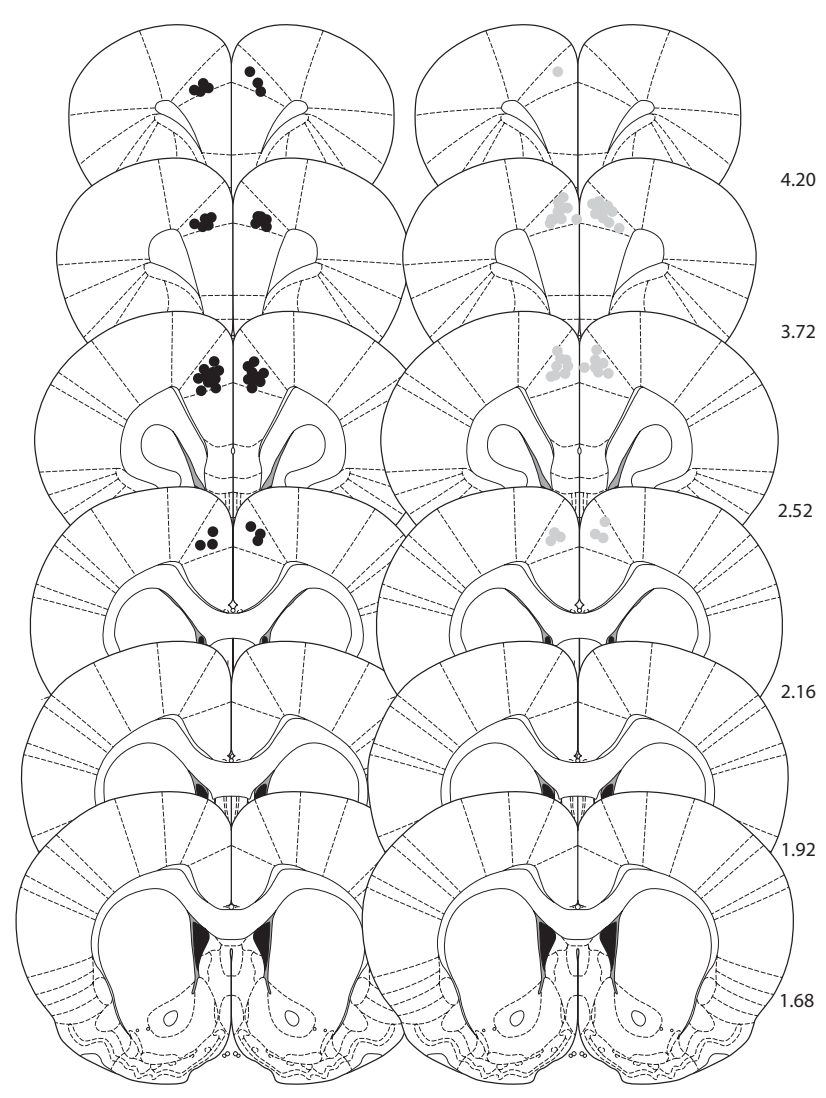

Figure 5. Histological verification of cannula placements for rats used in experiments 1-4. Approximate locations of infusion tips, in the ACgx. The black dots (left panel) represent the location of the injector tips in experiments 1 and 2; the gray dots (right panel) the location of the injector tips in experiments 3 and 4. Placements are shown on coronal plates adapted from Paxinos and Watson (1998) with numbers indicating distance from bregma in millimeters.

\section{Acknowledgments}

This work was supported by the BBSRC (ref. BB/K004980/1). We thank Tobias Bast for comments and advice and Clare Spicer and Ian Topham for technical assistance.

\section{References}

Akirav I, Maroun M. 2006. Ventromedial prefrontal cortex is obligatory for consolidation and reconsolidation of object recognition memory. Cereb Cortex 16: 1759-1765.

Baker KB, Kim JJ. 2002. Effects of stress and hippocampal NMDA receptor antagonism on recognition memory in rats. Learn Mem 9: 58-65.

Banks PJ, Bashir ZI, Brown MW. 2012. Recognition memory and synaptic plasticity in the perirhinal and prefrontal cortices. Hippocampus 22: 2012-2031.

Barbosa FF, Santos JR, Meurer YS, Macêdo PT, Ferreira LM, Pontes IM, Ribeiro AM, Silva RH. 2013. Differential cortical c-Fos and Zif-268 expression after object and spatial memory processing in a standard or episodic-like object recognition task. Front Behav Neurosci 7: 112.

Barker GR, Bird F, Alexander V, Warburton EC. 2007. Recognition memory for objects, place, and temporal order: a disconnection analysis of the role of the medial prefrontal cortex and perirhinal cortex. J Neurosci 27: 2948-2957.

Bast T, Feldon J. 2003. Hippocampal modulation of sensorimotor processes. Prog Neurobiol 70: $319-345$.

Brown MW, Aggleton JP. 2001. Recognition memory: what are the roles of the perirhinal cortex and hippocampus? Nat Rev Neurosci 2: 51-61.

Brown MW, Warburton EC, Aggleton JP. 2010. Recognition memory: material, processes, and substrates. Hippocampus 20: 1228-1244. 
Bussey TJ, Muir JL, Aggleton JP. 1999. Functionally dissociating aspects of event memory: the effects of combined perirhinal and postrhinal cortex lesions on object and place memory in the rat. J Neurosci 19: 495-502.

Clark RE, Zola SM, Squire LR. 2000. Impaired recognition memory in rats after damage to the hippocampus. J Neurosci 20: 8853-8860.

Dere E, Huston JP, De Souza Silva MA. 2007. The pharmacology, neuroanatomy and neurogenetics of one-trial object recognition in rodents. Neurosci Biobehav Rev 31: 673-704.

Einarsson EÖ, Nader K. 2012. Involvement of the anterior cingulate cortex in formation, consolidation, and reconsolidation of recent and remote contextual fear memory. Learn Mem 19: 449-452.

Ennaceur A, Delacour J. 1988. A new one-trial test for neurobiological studies of memory in rats. 1: behavioral data. Behav Brain Res 31: 47-59.

Ennaceur A, Neave N, Aggleton JP. 1997. Spontaneous object recognition and object location memory in rats: the effects of lesions in the cingulate cortices, the medial prefrontal cortex, the cingulum bundle and the fornix. Exp Brain Res 113: 509-519.

Frankland PW, Bontempi B. 2005. The organization of recent and remote memories. Nat Rev Neurosci 6: 119-130.

Hammond RS, Tull LE, Stackman RW. 2004. On the delay-dependent involvement of the hippocampus in object recognition memory. Neurobiol Learn Mem 82: 26-34.

Hannesson DK, Howland JG, Phillips AG. 2004a. Interaction between perirhinal and medial prefrontal cortex is required for temporal order but not recognition memory for objects in rats. J Neurosci 24: $4596-4604$.

Hannesson DK, Vacca G, Howland JG, Phillips AG. 2004b. Medial prefrontal cortex is involved in spatial temporal order memory but not spatial recognition memory in tests relying on spontaneous exploration in rats. Behav Brain Res 153: 273-285.

Jones BF, Witter MP. 2007. Cingulate cortex projections to the parahippocampal region and hippocampal formation in the rat. Hippocampus 17: 957-976.

King MV, Sleight AJ, Woolley ML, Topham IA, Marsden CA, Fone KC. 2004. 5-HT6 receptor antagonists reverse delay-dependent deficits in novel object discrimination by enhancing consolidation - an effect sensitive to NMDA receptor antagonism. Neuropharmacology 47: 195-204.

Lavenex P, Suzuki WA, Amaral DG. 2002. Perirhinal and parahippocampal cortices of the macaque monkey: projections to the neocortex. J Comp Neurol 447: 394-420.

Lyon L, Saksida LM, Bussey TJ. 2012. Spontaneous object recognition and its relevance to schizophrenia: a review of findings from pharmacological, genetic, lesion and developmental rodent models. Psychopharmacology (Berl) 220: 647-672.

Majchrzak M, Di Scala G. 2000. GABA and muscimol as reversible inactivation tools in learning and memory. Neural Plast 7: 19-29.

Meunier M, Bachevalier J, Mishkin M. 1997. Effects of orbital frontal and anterior cingulate lesions on object and spatial memory in rhesus monkeys. Neuropsychologia 35: 999-1015.

Myers RD, Tytell M, Kawa A, Rudy T. 1971. Micro-injection of $3 \mathrm{H}$-acetylcholine, $14 \mathrm{C}$-serotonin and $3 \mathrm{H}$-norepinephrine into the hypothalamus of the rat: diffusion into tissue and ventricles. Physiol Behav 7: 743-751.

Nelson AJ, Cooper MT, Thur KE, Marsden CA, Cassaday HJ. 2011. The effect of catecholaminergic depletion within the prelimbic and infralimbic medial prefrontal cortex on recognition memory for recency, location, and objects. Behav Neurosci 125: 396-403.

Paxinos G, Watson C. 1998. The rat brain in stereotaxic coordinates, 4 th. ed. Academic Press, New York.

Pezze MA, Marshall HJ, Fone KC, Cassaday HJ. 2015. Dopamine D1 receptor stimulation modulates the formation and retrieval of novel object recognition memory: role of the prelimbic cortex. Eur Neuropsychopharmacol 25: 2145-2156.
Rainer G, Miller EK. 2000. Effects of visual experience on the representation of objects in the prefrontal cortex. Neuron 27: 179-189.

Romero-Granados R, Fontán-Lozano A, Delgado-García JM, Carrión AM. 2010. From learning to forgetting: behavioral, circuitry, and molecular properties define the different functional states of the recognition memory trace. Hippocampus 20: 584-595.

Rossato JI, Radiske A, Kohler CA, Gonzalez C, Bevilaqua LR, Medina JH, Cammarota M. 2013. Consolidation of object recognition memory requires simultaneous activation of dopamine D1/D5 receptors in the amygdala and medial prefrontal cortex but not in the hippocampus. Neurobiol Learn Mem 106: 66-70.

Routtenberg A. 1972. Intracranial chemical injection and behavior: a critical review. Behav Biol 7: 601-641.

Schweimer J, Hauber W. 2006. Dopamine D1 receptors in the anterior cingulate cortex regulate effort-based decision making. Learn Mem 13: $777-782$.

Sesack SR, Deutch AY, Roth RH, Bunney BS. 1989. Topographical organization of the efferent projections of the medial prefrontal cortex in the rat: an anterograde tract-tracing study with Phaseolus vulgaris leucoagglutinin. J Comp Neurol 290: 213-242.

Squire LR, Bayley PJ. 2007. The neuroscience of remote memory. Curr Opin Neurobiol 17: 185-196.

Wang J, Bast T, Wang YC, Zhang WN. 2015. Hippocampus and two-way active avoidance conditioning: contrasting effects of cytotoxic lesion and temporary inactivation. Hippocampus 25: 1517-1531.

Warburton EC, Brown MW. 2010. Findings from animals concerning when interactions between perirhinal cortex, hippocampus and medial prefrontal cortex are necessary for recognition memory. Neuropsychologia 48: 2262-2272.

Watson DJ, Loiseau F, Ingallinesi M, Millan MJ, Marsden CA, Fone KC. 2012. Selective blockade of dopamine D3 receptors enhances while D2 receptor antagonism impairs social novelty discrimination and novel object recognition in rats: a key role for the prefrontal cortex. Neuropsychopharmacology 37: 770-786.

Weible AP, Rowland DC, Pang R, Kentros C. 2009. Neural correlates of novel object and novel location recognition behavior in the mouse anterior cingulate cortex. J Neurophysiol 102: 2055-2068.

Weible AP, Rowland DC, Monaghan CK, Wolfgang NT, Kentros CG. 2012. Neural correlates of long-term object memory in the mouse anterior cingulate cortex. J Neurosci 32: 5598-5608.

Winters BD, Bussey TJ. 2005a. Transient inactivation of perirhinal cortex disrupts encoding, retrieval, and consolidation of object recognition memory. J Neurosci 25: 52-61.

Winters BD, Bussey TJ. 2005b. Glutamate receptors in perirhinal cortex mediate encoding, retrieval, and consolidation of object recognition memory. J Neurosci 25: 4243-4251.

Winters BD, Saksida LM, Bussey TJ. 2008. Object recognition memory: neurobiological mechanisms of encoding, consolidation and retrieval. Neurosci Biobehav Rev 32: 1055-1070.

Xiang JZ, Brown MW. 2004. Neuronal responses related to long-term recognition memory processes in prefrontal cortex. Neuron 42: $817-829$.

Zhu XO, Brown MW, Aggleton JP. 1995a. Neuronal signalling of information important to visual recognition memory in rat rhinal and neighbouring cortices. Eur J Neurosci 7: 753-765.

Zhu XO, Brown MW, McCabe BJ, Aggleton JP. 1995b. Effects of the novelty or familiarity of visual stimuli on the expression of the immediate early gene c-Fos in rat brain. Neuroscience 69: 821-829.

Received January 4, 2017; accepted in revised form April 21, 2017. 


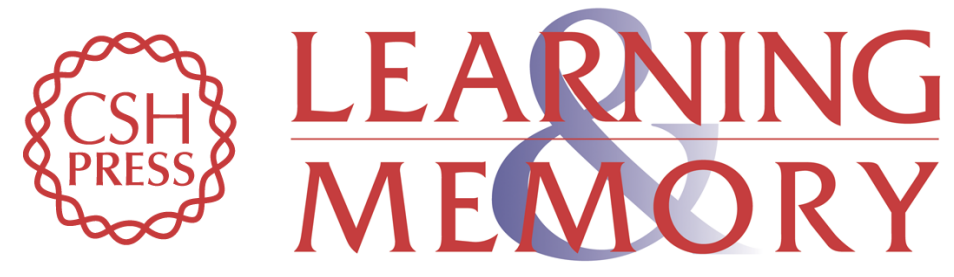

\section{Role of the anterior cingulate cortex in the retrieval of novel object recognition memory after a long delay}

Marie A. Pezze, Hayley J. Marshall, Kevin CF. Fone, et al.

Learn. Mem. 2017, 24:

Access the most recent version at doi:10.1101/Im.044784.116

References This article cites 45 articles, 10 of which can be accessed free at: http://learnmem.cshlp.org/content/24/7/310.full.html\#ref-list-1

Creative This article, published in Learning \& Memory, is available under a Creative Commons Commons License License (Attribution-NonCommercial 4.0 International), as described at http://creativecommons.org/licenses/by-nc/4.0/.

Email Alerting Receive free email alerts when new articles cite this article - sign up in the box at the Service top right corner of the article or click here. 